University of Nebraska - Lincoln

DigitalCommons@University of Nebraska - Lincoln

Faculty Publications from the Harold W. Manter Laboratory of Parasitology

2001

PHYLOGENY OF STEINERNEMA TRAVASSOS, 1927

(CEPHALOBINA: STEINERNEMATIDAE) INFERRED FROM

RIBOSOMAL DNA SEQUENCES AND MORPHOLOGICAL

CHARACTERS

\author{
S. Patricia Stock \\ University of California - Davis \\ James F. Campbell \\ USDA-ARS, james.campbell@usda.gov \\ Steven A. Nadler \\ University of California - Davis, sanadler@ucdavis.edu
}

Follow this and additional works at: https://digitalcommons.unl.edu/parasitologyfacpubs

Part of the Parasitology Commons

Stock, S. Patricia; Campbell, James F.; and Nadler, Steven A., "PHYLOGENY OF STEINERNEMA

TRAVASSOS, 1927 (CEPHALOBINA: STEINERNEMATIDAE) INFERRED FROM RIBOSOMAL DNA SEQUENCES AND MORPHOLOGICAL CHARACTERS" (2001). Faculty Publications from the Harold W. Manter Laboratory of Parasitology. 709.

https://digitalcommons.unl.edu/parasitologyfacpubs/709

This Article is brought to you for free and open access by the Parasitology, Harold W. Manter Laboratory of at DigitalCommons@University of Nebraska - Lincoln. It has been accepted for inclusion in Faculty Publications from the Harold W. Manter Laboratory of Parasitology by an authorized administrator of DigitalCommons@University of Nebraska - Lincoln. 


\title{
PHYLOGENY OF STEINERNEMA TRAVASSOS, 1927 (CEPHALOBINA: STEINERNEMATIDAE) INFERRED FROM RIBOSOMAL DNA SEQUENCES AND MORPHOLOGICAL CHARACTERS
}

\author{
S. Patricia Stock, James F. Campbell, ${ }^{*}$ and Steven A. Nadler \\ Department of Nematology, University of California, Davis, California 95616-8668
}

\begin{abstract}
Entomopathogenic nematodes in Steinernema, together with their symbiont bacteria Xenorhabdus, are obligate and lethal parasites of insects that can provide effective biological control of some important lepidopteran, dipteran, and coleopteran pests of commercial crops. Phylogenetic relationships among 21 Steinernema species were estimated using 28S ribosomal DNA (rDNA) sequences and morphological characters. Sequences of the rDNA internal transcribed spacers were obtained to provide additional molecular characters to resolve relationships among Steinernema carpocapsae, Steinernema scapterisci, Steinernema siamkayai, and Steinernema monticolum. Four equally parsimonious trees resulted from combined analysis of $28 \mathrm{~S}$ sequences and 22 morphological characters. Clades inferred from analyses of molecular sequences and combined datasets were primarily reliably supported as assessed by bootstrap resampling, whereas those inferred from morphological data alone were not. Although partially consistent with some traditional expectations and previous phylogenetic studies, the hypotheses inferred from molecular evidence, and those from combined analysis of morphological and molecular data, provide a new and comprehensive framework for evaluating character evolution of steinernematids. Interpretation of morphological character evolution on 6 trees inferred from sequence data and combined evidence suggests that many structural features of these nematodes are highly homoplastic, and that some structures previously used to hypothesize relationships represent ancestral character states.
\end{abstract}

Nematodes in Steinernema Travassos, 1927 (Steinernematidae) are obligate and lethal parasites of insects. Steinernematids harbor bacterial symbionts, Xenorhabdus spp., that kill the insect host and digest tissues, thereby providing nutrients suitable for nematode growth and development within the insect cadaver (Boemare et al., 1993; Forst and Nealson, 1996). Steinernema species are distributed worldwide, having been reported from all continents except Antarctica (Griffin et al., 1990). Steinernema species and isolates exhibit differences in behavior, host range, infectivity, and environmental tolerances, and this variability has stimulated interest in finding new strains and species that are potentially useful for biological control, including commercial applications (Simoes and Sosa, 1996; Brown and Gaugler, 1997; Campbell and Gaugler, 1997; de Doucet et al., 1999).

Currently, Steinernema comprises 25 described species. However, many additional isolates from diverse geographic localities have yet to be fully characterized. Steinernema spp. have been described through the implicit application of several different species concepts, with morphological or morphometric data and cross-breeding tests most frequently used for differential diagnosis and identification (Poinar, 1990; Dix et al., 1994; Hominick et al., 1997; Kaya and Stock, 1997; Nguyen and Smart, 1997). Applying the biological species concept via cross-breeding tests is labor and time intensive, and interpretation of morphological features for identification requires substantial expertise and experience to ensure accuracy. In attempts to overcome these difficulties, approaches using molecular evidence, e.g., random amplified polymorphic DNA (RAPD), restriction fragment length polymorphism (RFLP), or molecular and morphological evidence have been used to characterize steinernematids (Reid and Hominick, 1993; Joyce et al., 1994; Liu and Berry, 1995; Grenier et al., 1996; Stock et al., 1998). Although nucleotide sequence data have been used to delimit

Received 5 September 2000; revised 19 January 2001; accepted 19 January 2001.

* USDA, ARS, Biological Research Unit(BRU), Grain Marketing and Production Research Center (GMPRC), 1515 College Avenue, Manhattan, Kansas66502. nematode species and infer their evolutionary history (Nadler, 1992; Adams, 1998; Adams et al., 1998; Blaxter et al., 1998; Kampfer et al., 1998; Nadler and Hudspeth, 1998, 2000; Nadler, Adams et al., 2000), sequence-based studies of steinernematids have been limited (Liu, Berry, and Moldenke, 1997).

The first explicit evolutionary hypothesis for the Steinernematidae was proposed by Poinar (1993) based on his interpretation and weighting of morphological, biological, physiological, and distributional evidence. Poinar (1993) concluded that Steinernema species evolved from a proto-Rhabditonema ancestor in a terrestrial environment about 375 million yr ago. Explicit hypotheses for relationships among Steinernema spp. were first proposed by Reid (1994) and were based on phenetic analysis of genetic distances calculated from ribosomal DNA (rDNA) restriction sites for 12 species. Additional investigations have been based on rDNA RFLP patterns (Reid et al., 1997), combined analyses of morphological data and RAPD markers (Liu and Berry, 1996), or partial sequences of $18 \mathrm{~S}$ rDNA (Liu, Berry, and Moldenke, 1997). Unfortunately, the evolutionary hypotheses obtained from these studies are of limited utility due to several factors, including an insufficient number of phylogenetically informative characters, and in certain cases, the use of data, e.g., RAPD markers, or tree-building methods, e.g., UPGMA phenograms, that are inappropriate for inferring evolutionary history. In addition, although different isolates of individual species were included in some of these studies, less than half of the described Steinernema spp. have been studied.

In the present investigation, phylogenetic relationships among 21 Steinernema species, including representatives of all recognized species that were available as living isolates at the time this study was initiated, were estimated using nuclear large-subunit (LSU) rDNA sequences and morphological characters. The phylogenetic trees resulting from combined analysis of molecular and morphological data, and those from analysis of sequence data alone, were used to delimit species and develop hypotheses for the evolution of morphological features by parsimony mapping. 


\section{MATERIALS AND METHODS}

\section{Source and propagation of taxa}

Twenty-two Steinernema isolates representing 21 described species were studied (Table I). Three taxa, Cervidellus alutus (Cephalobidae), Pseudacrobeles variabilis (Cephalobidae), and Panagrellus redivivus (Panagrolaimidae), were selected as outgroups based on results from analyses of small subunit (SSU, 18S) rDNA (Blaxter et al., 2000; Félix et al., 2000) and preliminary analysis of Cephalobina LSU (28S) ribosomal sequences (S. A. Nadler, pers. comm.). Steinernema isolates were reared in vivo using last-instar Galleria mellonella (L.) larvae as hosts (Kaya and Stock, 1997), except for Steinernema scapterisci that was reared in adults of Acheta domestica (L.), and Steinernema kushidai that was reared in larvae of Cyclocephala hirta Leconte. Cervidellus alutus, $P$. variabilis, and $P$. redivivus (Table I) were reared on babyfood agar (1\% agar and $0.5 \%$ Beech-Nut Stages mixed cereal with calcium and iron [Beech-Nut Nutrition Corporation, Canajoharie, New York]) maintained at $15 \mathrm{C}$ in Parafilm-sealed plastic petri plates.

\section{DNA amplification and sequencing}

With the exception of 2 species, nucleic acid preparations used for polymerase chain reaction (PCR) amplifications of Steinernema spp. were extracted from 1 first-generation female. For S. scapterisci and Steinernema abbasi, pooled samples of several thousand infective juveniles reared from A. domestica or G. mellonella, respectively, were washed 3 times with Ringer's solution (Woodring and Kaya, 1988) and used for nucleic acid extraction. For each outgroup species, 10-100 adults were pooled and used for nucleic acid extraction. For Steinernema adults, $P$. variabilis, and $P$. redivivus, nucleic acids were extracted using a DNA binding (glass milk) method employing isothiocyanate and guanidinium (ID Pure Genomic DNA Kit, ID Labs Biotechnology; London, Ontario, Canada). Nucleic acids obtained using this method were not quantified prior to use in PCR amplifications. Instead, the elution containing nucleic acids was concentrated by vacuum evaporation and standardized to $12 \mu \mathrm{l}$ using TE buffer ( $\mathrm{pH} 7.0$ ), and $2 \mu 1$ of this preparation was used for each PCR reaction. For C. alutus, S. scapterisci, and S. abbasi, nematodes were incubated at $50 \mathrm{C}$ in $\mathrm{pH} 8.0 \mathrm{TE}$ buffer (Ausubel et al., 1989) containing proteinase K (1 $\mu \mathrm{g} / \mu \mathrm{l}$ final concentration; Sigma, St. Louis, Missouri) and digested until only cuticle remained. Nucleic acids were extracted from the digestion supernatant using phenol-chloroform enrichment, ethanol/ammonium acetate precipitation (Ausubel et al., 1989). The resulting pellet was washed with $70 \%$ ethanol, resuspended in TE buffer $(\mathrm{pH} \mathrm{8.0)}$, treated with 50 $\mu \mathrm{g}$ of RNAse A (1 hr at $37 \mathrm{C})$, and DNA recovered following reprecipitation with ethanol. DNA from phenol-chloroform extracts was quantified by spectrophotometry, and 100-200 ng used per PCR reaction.

PCR was used to amplify a region within the $5^{\prime}$-end of the nuclear LSU rDNA that included the D2 and D3 domains. Design of the forward PCR primer (no. 391, 5'-AGCGGAGGAAAAGAAACTAA, positions 3,745-3,764 in Caenorhabditis elegans GenBank X03680) was described in Nadler and Hudspeth (1998). The reverse primer (no. 501, 5'-TCGGAAGGAACCAGCTACTA, positions $4,681-4,700$ ) was designed by Thomas et al. (1997). PCR conditions, e.g., annealing temperature and $\mathrm{MgCl}_{2}$ concentration, were adjusted empirically to optimize reaction specificity for individual species. Proofreading polymerase (ID Proof, ID Labs Biotechnology, or Finnzymes DyNAzyme EXT, MJ Research, Watertown, Massachusetts) was used for PCR amplification. Typical PCR reactions included $0.5 \mu \mathrm{M}$ of each primer, $200 \mu \mathrm{M}$ deoxynucleoside triphosphates, and a $\mathrm{MgCl}_{2}$ concentration of $2 \mathrm{mM}$ in a total reaction volume of $25 \mu \mathrm{l}$. PCR cycling parameters typically included denaturation at $94 \mathrm{C}$ for $3 \mathrm{~min}$, followed by 33 cycles of 94 $\mathrm{C}$ for $30 \mathrm{sec}, 52 \mathrm{C}$ for $30 \mathrm{sec}$, and $72 \mathrm{C}$ for $1 \mathrm{~min}$, followed by a postamplification extension at $72 \mathrm{C}$ for $7 \mathrm{~min}$.

A region of nuclear rDNA, including the $18 \mathrm{~S} 33^{\prime}$-terminus, internal transcribed spacers (ITS-1, ITS-2), 5.8S subunit, and $28 \mathrm{~S} 5^{\prime}$-terminus, was amplified by PCR in 6 Steinernema species (Steinernema affine, Steinernema carpocapsae, Steinernema intermedium, Steinernema monticolum, S. scapterisci, and Steinernema siamkayai). The strategy for design of these ITS primers was described previously (Nadler, Hoberg et al., 2000). The forward primer anneals to the $3^{\prime}$-terminus of the SSU rDNA (primer no. 93, 2,635-2,653 5'-TTGAACCGGGTAAAAGTCG), and the reverse primer anneals to the 5 '-terminus of the LSU rDNA (no. 94, 3,745-3,764 5'-TTAGTTTCTTTTCCTCCGCT). The PCR reaction mix was the same as described previously for the LSU reactions. PCR cycling parameters included denaturation at $94 \mathrm{C}$ for $4 \mathrm{~min}$, followed by 33 cycles of $94 \mathrm{C}$ for $30 \mathrm{sec}, 60 \mathrm{C}$ for $30 \mathrm{sec}$, and $72 \mathrm{C}$ for $50 \mathrm{sec}$, followed by a postamplification extension at $72 \mathrm{C}$ for $7 \mathrm{~min}$.

One microliter of each PCR amplification was used for agarose gel electrophoresis $(1.3 \%$ agarose in $1 \times \mathrm{TBE}$ buffer) to confirm product size and yield. PCR products were prepared for direct sequencing using spin-filtration or enzymatic treatment with exonuclease I and shrimp alkaline phosphatase (PCR product Presequencing Kit, Amersham Corporation, Piscataway, New Jersey). For spin-filtration, excess PCR primers and dNTPs were removed by washing the product 3 times with $0.1 \times$ TE buffer ( $\mathrm{pH}$ 8.0) using a Millipore filter (Ultrafree-MC 30,000 NMWL; Millipore Corporation, Bedford, Massachusetts). Sequencing reactions were performed using BigDye (Perkin-Elmer, Norwalk, Connecticut) terminator cycle sequencing chemistry, and reaction products were separated and detected using an ABI 377 automated DNA sequencer. Sequences for each species were completely double-stranded for accuracy using the PCR primers and internal sequencing primers as required. For LSU sequences of Steinernema spp., forward internal sequencing primers included no. 502 (5'-CAAGTACCGTGAGGGAAAGTTGC) and no. 539 (5'-GGATTTCCTTAGTAACTGCGAGTG); reverse internal sequencing primers were no. 503 (5'-CCTTGGTCCGTGTTTCAAGACG) or no. 390 (5'-ATCCGTGTTTCAAGACGGG). To obtain LSU sequences for outgroup species, the forward internal primer no. 504 (5'-CAAGTACCGTGAGGGAAAGTTG) was used; reverse primers no. 390 , no. 503, no. 535 (5'-TAGTCTTTCGCCCCTATAC), and no. 536 (5'-CAGCTATCCTGAGGGAAAC) were used as required. ITS and 5.8S sequences of Steinernema species were double-stranded using the internal forward sequencing primer no. 533 (5'-CAAGTCTTATCGGTGGATCAC) and the reverse internal primer no. $534\left(5^{\prime}\right.$ GCAATTCACGCCAAATAACGG). LSU and ITS sequences are deposited in GenBank (AF143368, AF331888-AF331917) (Table I).

\section{Sequence analysis}

Contig assembly and sequence ambiguity resolution was performed with the aid of Sequencher version 3.0 (Gene Codes, Ann Arbor, Michigan). Sequences corresponding to the PCR amplification primers were removed prior to multiple sequence alignment and phylogenetic analysis, because primer incorporation during amplification masks potential mismatches (substitutions) that may occur in priming sites. Sequences were aligned initially using CLUSTAL $X$ version $1.53 \mathrm{~b}$ (Thompson et al., 1997), and the resulting output was adjusted manually to improve homology statements. For the LSU region of Steinernema spp. and outgroups, this yielded an alignment of 1,072 characters (the full alignment, LSU FA). The effect of alignment ambiguity on phylogenetic analysis of these LSU data was explored by producing a second data matrix (minus uncertainty, LSU MUNC) from the LSU FA that excluded 293 characters of the FA for which inferences of positional homology were considered potentially ambiguous. A third dataset (gap recoded, LSU GR) was produced from the LSU MUNC dataset by recoding each unambiguous contiguous gap (indel) as 1 character, with nucleotide present or absent as the alternative character states (Swofford, 1993; Crandall and Fitzpatrick, 1996). This recoding yielded 14 additional characters, of which 9 were parsimony-informative.

The multiple alignment of 6 Steinernema ITS sequences (859 characters) included several long regions with substantial alignment ambiguity; therefore, only the alignment with ambiguous regions removed (ITS MUNC, 538 characters) or a gap-recoded dataset derived from ITS MUNC dataset (ITS GR, 549 characters) was used for phylogenetic analysis. The gap-recoded ITS dataset had 6 additional parsimony-informative characters.

Sequence data were analyzed by unweighted maximum parsimony (MP) using PAUP* version 4.0b3a (Swofford, 1998). Unrecoded gaps were treated as missing data. Tree searches of the LSU datasets were performed using heuristic methods with TBR (tree-bisection reconnection) branch swapping, and a minimum of 500 replicates of random stepwise addition. For the ITS datasets, MP searches were performed using the branch-and-bound method. Reported consistency indices (C.I.) do not include uninformative characters. Bootstrap parsimony analyses were performed using heuristic searches (simple stepwise addition, TBR branch-swapping, MULPARS) and 2,000 replicates. Datasets and tree- 
TABLE I. Specimen, source, voucher, and GenBank accession information for taxa used in phylogenetic analyses; taxon numbers are used in parenthetical tree descriptions.

\begin{tabular}{|c|c|c|c|c|c|}
\hline Species & Isolate name & $\begin{array}{l}\text { Geographic } \\
\text { origin }\end{array}$ & $\begin{array}{l}\text { Voucher } \\
\text { specimens }\end{array}$ & $\begin{array}{c}\text { GenBank } \\
\text { accession no. }\end{array}$ & Source \\
\hline 1. Steinernema abbasi Elawad, Ahmad, and Reid, 1997 & & Sultanate of Oman & UCDNC 3742-3744 & AF331890* & B. R. Briscoe \\
\hline 2. Steinernema affine (Bovien, 1937) & B1 & England & UCDNC 3745-3747 & $\begin{array}{l}\text { AF331899* } \\
\text { AF331912† }\end{array}$ & B. R. Briscoe \\
\hline 3. Steinernema arenarium (Artyukhovsky, 1967) & & Voronezh, Central Russia & UCDNC $3748-3750$ & AF331892* & H. K. Kaya \\
\hline 4. Steinernema bicornutum Tallosi, Peters, and Ehlers, 1995 & & Vojvodina, Yugoslavia & UCDNC $3751-3753$ & AF331904* & R. U. Ehlers \\
\hline 5. Steinernema carpocapsae (Weiser, 1955) & All & Georgia, USA & UCDNC 3754-3757 & $\begin{array}{l}\text { AF331900* } \\
\text { AF331913† }\end{array}$ & H. K. Kaya \\
\hline 6. Steinernema ceratophorum Jian, Reid, and Hunt, 1997 & & Jining, China & UCDNC $3807-3810$ & AF331888* & B. R. Briscoe \\
\hline 7. Steinernema cubanum Mracek, Hernandez, and Boemare, 1994 & & Pinar del Rio, Cuba & UCDNC $3758-3760$ & AF331889* & Z. Mracek \\
\hline 8. Steinernema feltiae (Filipjev, 1934) & Bodega Bay & California, USA & UCDNC 3761-3763 & AF331906* & S. P. Stock \\
\hline 9. Steinernema glaseri (Steiner, 1929) & $\mathrm{NC}$ & North Carolina, USA & UCDNC 3764-3766 & AF331908* & H. K. Kaya \\
\hline 10. Steinernema intermedium (Poinar, 1985) & $\mathrm{SC}$ & South Carolina, USA & UCDNC 3767-3769 & $\begin{array}{l}\text { AF331909* } \\
\text { AF331916† }\end{array}$ & H. K. Kaya \\
\hline 11. Steinernema karii Waturu, Hunt, and Reid, 1997 & & Kirinyaga, Kenya & UCDNC 3770-3772 & AF331902* & B. R. Briscoe \\
\hline 12. Steinernema kraussei (Steiner, 1923) & Westphalia & Westphalia, Germany & UCDNC $3773-3775$ & AF331896* & Z. Mracek \\
\hline 13. Steinernema kushidai Mamiya, 1988 & & Shizouka, Japan & UCDNC $3776-3778$ & AF331897* & H. K. Kaya \\
\hline 14. Steinernema longicaudum Shen and Wang, 1992 & CF1 VII & $\begin{array}{l}\text { Lake Tahoe, California, } \\
\text { USA }\end{array}$ & UCDNC 3779-3781 & AF331901* & S. P. Stock \\
\hline 15. S. longicaudum & & Shandong, China & UCDNC 3782-3784 & AF331894* & B. R. Briscoe \\
\hline 16. Steinernema monticolum Stock, Choo, and Kaya, 1997 & Mt. Chiri & Gyeongnam, Korea & UCDNC 3785-3787 & $\begin{array}{l}\text { AF331895* } \\
\text { AF331914† }\end{array}$ & S. P. Stock \\
\hline 17. Steinernema oregonense Liu and Berry, 1996 & OS-10 & Oregon, USA & UCDNC 3788-3791 & AF331891* & J. Liu \\
\hline 18. Steinernema puertoricense Román and Figueroa, 1994 & & Loiza, Puerto Rico & UCDNC 3792-3794 & AF331903* & J. Román \\
\hline 19. Steinernema rarum (de Doucet, 1986) & Sargento Cabral & Córdoba, Argentina & UCDNC 3795-3797 & AF331905* & M. M. de Doucet \\
\hline 20. Steinernema riobrave Cabanillas, Poinar, and Raulston, 1994 & $\mathrm{TX}$ & Texas, USA & UCDNC $3798-3800$ & AF331893* & H. K. Kaya \\
\hline 21. Steinernema scapterisci Nguyen and Smart, 1992 & Colón & Buenos Aires, Argentina & UCDNC 3801-3803 & $\begin{array}{l}\text { AF331898* } \\
\text { AF331915† }\end{array}$ & S. P. Stock \\
\hline 22. Steinernema siamkayai Stock, Somsook, and Kaya, 1998 & T9 & Petchabun, Thailand & UCDNC 3804-3807 & $\begin{array}{l}\text { AF331907* } \\
\text { AF331917† }\end{array}$ & S. P. Stock \\
\hline 23. Cervidellus alutus (Siddiqi, 1993) & PDL 004 & Senegal & & AF331911* & P. De Ley \\
\hline 24. Pseudacrobeles variabilis (Steiner, 1936) & JB-056 & $\begin{array}{l}\text { Santa Anita, California, } \\
\text { USA }\end{array}$ & & AF143368* & J. Baldwin \\
\hline 25. Panagrellus redivivus (Linnaeus, 1767) & JB-129 & $\begin{array}{l}\text { Riverside, California, } \\
\text { USA }\end{array}$ & & AF331910* & J. Baldwin \\
\hline
\end{tabular}

* LSU sequences.

$*$ LSU sequences.
$\dagger$ ITS sequences.

USA 
files from analyses have been deposited in TreeBASE (Sanderson et al., 1994) as study S555.

Templeton's modified parsimony test (Templeton, 1983) and the Kishino-Hasegawa test (Kishino and Hasegawa, 1989) were used to compare alternative phylogenetic hypotheses to the combined evidence trees. Because previous investigations of Steinernema relationships included fewer species, alternative phylogenetic hypotheses were represented as the most parsimonious tree(s) including all 22 taxa consistent with the alternative topology.

\section{Morphological data}

Sixty specimens (20 first-generation males, 20 first-generation females, and 20 third-stage infective juveniles [IJ]) of each Steinernema isolate were used for characterization of morphological features. Specimens used for these morphological analyses were deposited in the University of California Davis Nematode Collection (Table I). A total of 22 morphological characteristics (14 qualitative and 8 quantitative), including those typically used for diagnosis of species (Hominick et al., 1997), were evaluated. Range, mean, and standard deviation were determined for 8 quantitative characteristics (Table II). For cladistic analysis, continuous traits were coded as discrete states employing Simon's (1983) homogenous subset coding method. One-way analysis of variance (ANOVA) was conducted for character values across the taxa using MSTAT-C version 2.0 (Freed et al., 1991). For all characters, groups were defined that were significantly different at $P<0.05$. This method confirmed the statistical distinctiveness of the groups within the sample, which is required for the application of subset gap coding. Finally, an a posteriori multiple comparisons test (Student-Newman-Keul's multiple-range test) was performed to establish the subsets (character states) within each character.

Morphological character states were based on our observations and measurements, except for IJ lateral-field pattern (Mrácek and Bednarek, 1991; Tallosi et al., 1994; Elawad et al., 1997; Nguyen and Smart, 1997; Stock, 1997; Waturu et al., 1997; Stock et al., 1998) and morphology of the gubernaculum cuneus (Hominick et al., 1997; Nguyen and Smart, 1997; Stock et al., 1998). Of 22 morphological characters, 7 were binary and 15 were multistate (Table III); 4 missing values were coded as ? Outgroup taxa were excluded from the morphological analysis because divergence precluded reliable assessments of homology for many of the characters used for Steinernema species. Trees inferred from morphological data or combined analysis of molecular and morphological data were rooted based on results of the molecular analyses.

Maximum parsimony analysis of morphological data was performed using PAUP* with all characters unordered and weighted equally. Searches for the most parsimonious trees were performed using a heuristic search strategy $(2,000$ replicates of random taxon addition, TBR branch swapping, MULPARS). Bootstrap parsimony analyses were performed using heuristic searches (simple stepwise addition, TBR branchswapping, maxtrees of 100 per replicate) with 2,000 replicates.

\section{RESULTS}

\section{Molecular phylogenetic analyses}

MP analysis of the LSU FA dataset (424 parsimony-informative characters) yielded 4 fully dichotomous trees (Fig. 1) of 1,372 steps (C.I. 0.61); there is minimal conflict among these trees as revealed by strict consensus (Fig. 1). Bootstrap MP analysis of the LSU FA dataset (Fig. 1) revealed moderate $(\geq 75 \%,<90 \%)$ to high ( $\geq 90 \%)$ support for most clades recovered in the strict consensus of most parsimonious trees. MP analysis of the LSU MUNC dataset (327 parsimony-informative characters) yielded 2 most parsimonious trees of 902 steps (C.I. $0.63)$. One of these trees was identical in topology to tree 3 from the LSU FA dataset (Fig. 1). The second tree differed from trees of the LSU FA analysis only in depicting relationships within 1 clade differently (((Steinernema ceratophorum, Steinernema bicornutum), S. abbasi), Steinernema riobrave). Bootstrap MP analysis of the LSU MUNC dataset (Fig. 1) yielded a $50 \%$ majority-rule consensus tree nearly identical in topology to the bootstrap tree from the FA dataset; the only difference was the recovery of a weakly supported clade (arguably, weakly supported ranges from $\geq 50 \%$ to $<75 \%$ ) consisting of S. scapterisci, S. carpocapsae, and S. siamkayai (63\%) in the LSU MUNC analysis. All 11 clades receiving high bootstrap support in analysis of the LSU FA dataset also received high support in analysis of the LSU MUNC dataset. Of 5 clades with moderate support in the LSU FA bootstrap tree, 4 had lower support in the LSU MUNC bootstrap analysis, and 1 had higher support. In addition, bootstrap values for the sister-taxa Steinernema longicaudum US and Steinernema karii increased from $64 \%$ (LSU FA) to $85 \%$ in the LSU MUNC analysis. MP analysis of the LSU GR dataset (336 parsimony-informative characters) yielded 2 most parsimonious trees of 919 steps (C.I. 0.63 ); these trees had the same topology as the most parsimonious trees from the LSU MUNC analysis. All 11 clades receiving high bootstrap support in the LSU FA, and MUNC datasets also received high support in bootstrap MP analysis of the LSU GR dataset (Fig. 1). In the LSU GR dataset, bootstrap values for moderately supported clades were similar to those obtained for the LSU MUNC analysis. The strict consensus of most parsimonious trees inferred from analysis of all individual LSU datasets (FA, MUNC, GR) retains considerable resolution (Fig. 2).

One clade of 4 Steinernema species (S. carpocapsae, S. monticolum, S. scapterisci, and S. siamkayai) was poorly resolved in strict consensus trees for individual LSU datasets and in bootstrap majority-rule consensus trees for these LSU data (Figs. 1, 2). Species in this clade had low levels of LSU sequence divergence (uncorrected pairwise difference of 0.19 $2.2 \%$ ) and relatively few parsimony-informative sequence sites (16 among these 4 species). Sequences from the ITS region provided 22 additional parsimony-informative characters among these 4 species, and the datasets for 6 species (the 4 species and 2 Steinernema outgroups) included 131 (ITS MUNC) or 137 (ITS GR) informative characters. MP analyses of the ITS MUNC and ITS GR datasets each yielded 1 tree (ITS MUNC 332 steps, ITS GR 343 steps, C.I. 0.79 and 0.80, respectively) of identical topology ((( (S. monticolum, S. scapterisci), S. carpocapsae), S. siamkayai), outgroups). Bootstrap MP analysis yielded support $\geq 97 \%$ for all clades in the ITS GR dataset, and $\geq 91 \%$ for clades in the ITS MUNC dataset. A combined MP analysis of ITS GR and LSU GR data for these 6 Steinernema spp. (4 ingroup and 2 outgroup species, 347 parsimony-informative characters) yielded 1 tree (585 steps, C.I. 0.89) with the same topology as inferred from analyses of the ITS MUNC and ITS GR datasets. Bootstrap MP analysis of these combined molecular data yielded the same tree with nodal support: 89\% (S. monticolum, S. scapterisci); 97\% (S. monticolum, S. scapterisci, S. carpocapsae). Molecular phylogenetic results are summarized in 2 trees (Fig. 3) that represent the 2 most parsimonious LSU GR trees, and the topology for S. carpocapsae, S. monticolum, S. scapterisci, and S. siamkayai as inferred from combined analysis of the ITS GR and LSU GR datasets. These molecular phylogenetic hypotheses that are inferred from truncated gap-recoded datasets exclude characters that may be confounded by alignment ambiguity yet maximize the number of parsimony-informative characters in the remaining data. 
TABLE II. Morphometric (quantitative) data (*) for males and infective juveniles; all measurements are in microns and are based on 20 individuals.

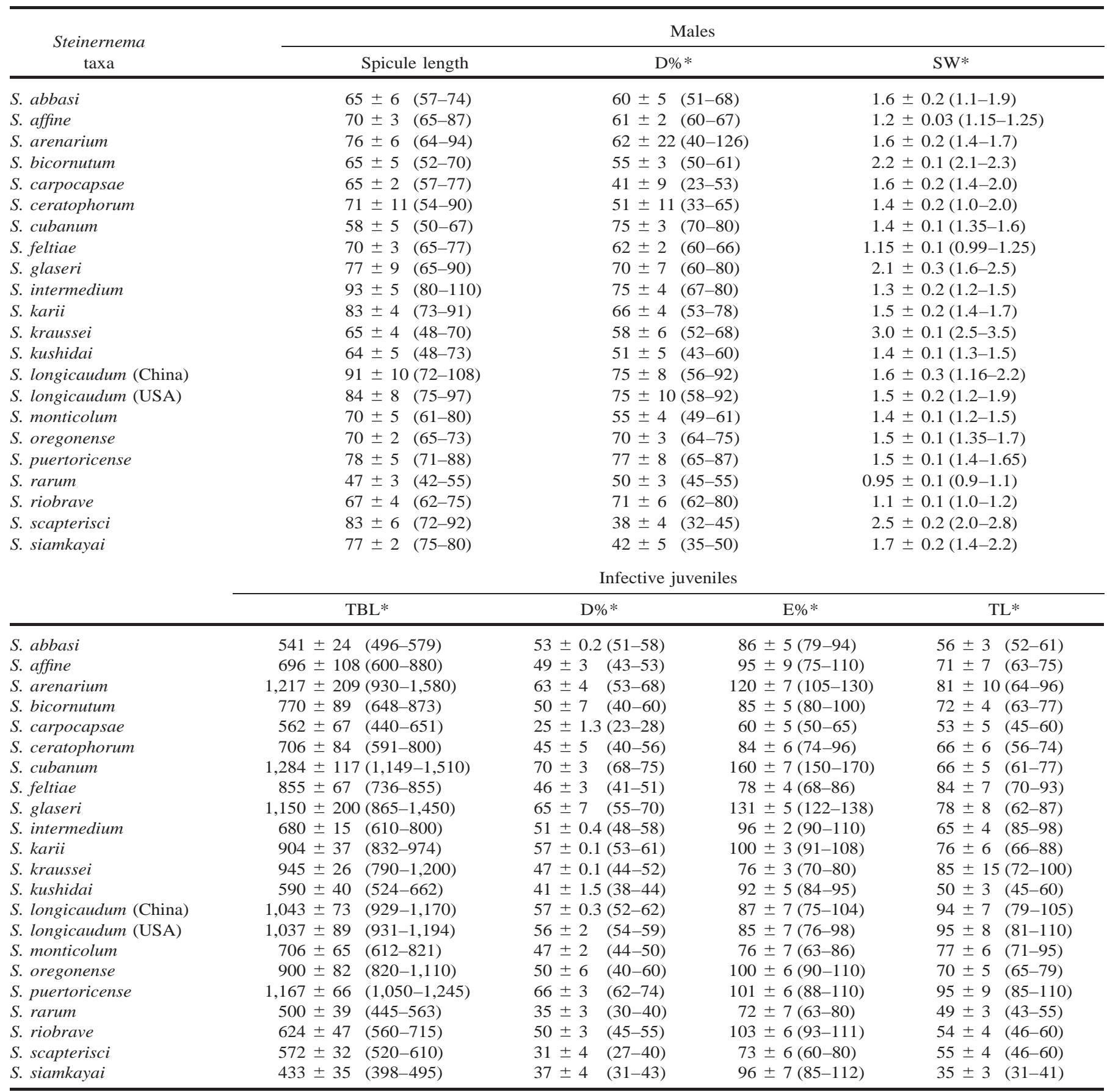

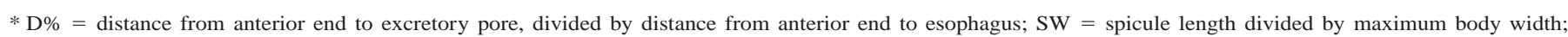
$\mathrm{TBL}=$ total body length; $\mathrm{E} \%=$ distance from anterior end to excretory pore, divided by tail length; TL $=$ tail length.

\section{Phylogenetic analysis of morphological data and combined evidence}

Phylogenetic analysis of 22 morphological characters yielded 3 most parsimonious trees of length 107 (C.I. 0.40). The strict consensus (Fig. 4) shows there is minimal conflict among these 3 trees; however, the bootstrap 50\% majority-rule consensus tree contained only 1 clade (United States and Chinese isolates of $S$. longicaudum, frequency of $84 \%$ ), with the remaining taxa collapsed in a polytomy.

MP analysis of the combined morphological and molecular (LSU GR dataset) evidence (815 characters, 307 parsimonyinformative) for Steinernema spp. yielded 4 equally parsimonious trees of 741 steps (C.I. 0.60). The strict consensus of these trees (Fig. 5) and bootstrap values for the combined evidence hypothesis (Fig. 5) show substantial similarity to results 
TABLE III. Morphological characters and character states for Steinernema species.

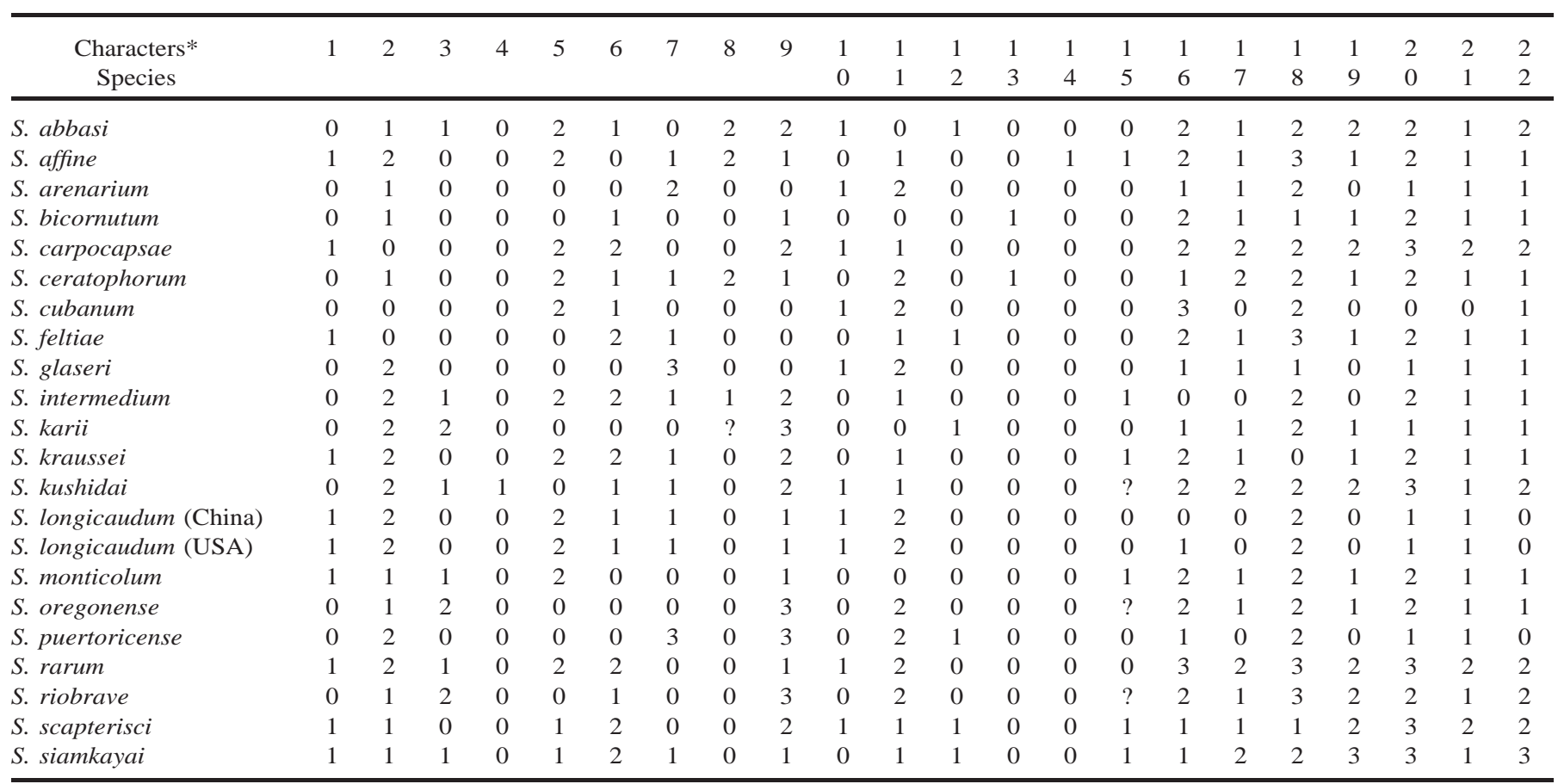

* 1, Male tail mucro, (0) absent, (1) present; 2, spicule shape, (0) slightly curved, (1) moderately curved, (2) strongly curved; 3, spicule manubrium shape, (0) longer than wide, (1) square-rounded, (2) wider than long; 4, spicule lamina notch, (0) absent, (1) present; 5, spicule velum, (0) absent, (1) present, reduced, (2) present, well developed; 6, spicule rostrum, (0) absent, (1) present, slightly developed, (2) present, well developed; 7, spicule tip, (0) pointed, (1) blunt, not swollen, (2) blunt and swollen, (3) hook-shaped; 8, gubernaculum cuneus, (0) short, Y or V-shaped, (1) short, needle-shaped, (2) long, needle-shaped; 9, female tail shape, (0) blunt without mucro, (1) blunt with mucro, (2) conoid with pointy terminus, (3) conoid with mamillate terminus; 10, female postanal swelling, (0) absent, (1) present; 11, vulval lips, (0) nonprotruding, (1) protruding and symmetric, (2) protruding and asymmetric; 12, female double-flapped epiptygma, (0) absent, (1) present; 13, IJ hornlike structures, (0) absent, (1) present; 14, IJ tail spine, (0) absent, (1) present; 15, IJ lateral field pattern, (0) 8 ridges, (1) less than 8 ridges; 16, spicule length, (0) more than $90 \mu \mathrm{m}$, (1) 71-90 $\mu \mathrm{m}$, (2) between 70 and $60 \mu \mathrm{m}$, (3) less than $60 \mu \mathrm{m} ; 17$, male D\%, (0) more than 75, (1) between 52 and 75, (2) less than $52 ; 18$, male SW ratio, (0) more than 2.9, (1) between 2.0 and 2.9, (2) between 1.2 and 1.9 , (3) less than $1.2 ; 19$, IJ total body length, (0) more than $1000 \mu \mathrm{m},(1)$ between 650 and $1,000 \mu \mathrm{m}$, (2) between 450 and $650 \mu \mathrm{m}$, (3) less than $450 \mu \mathrm{m} ; 20$, IJ D\%, (0) more than 70, (1) between 55 and 70, (2) between 45 and 54 , (3) less than 45; 21, IJ E\%, (0) more than 150, (1) 75-150, (2) less than 75; 22, IJ tail length, (0) more than $90 \mu \mathrm{m}$, (1) between 61 and $90 \mu \mathrm{m}$, (2) between 40 and $60 \mu \mathrm{m}$, (3) less than $40 \mu \mathrm{m}$.

inferred from the LSU datasets (Fig. 1). For example, the bootstrap MP trees inferred from combined evidence and molecular datasets have 13 clades in common. Nine of these clades have similar bootstrap values, 2 showed decreased support in the combined evidence tree, and 2 showed increased support in analysis of the combined evidence. Statistical evaluations of trees revealed that Liu, Berry, and Moldenke's (1997) alternative hypothesis was a significantly worse interpretation of these data (Table IV).

\section{Character evolution and species delimitation}

The composite trees (Fig. 3), inferred from molecular datasets (LSU GR and ITS GR), and the 4 most parsimonious trees from analysis of the combined evidence were used to determine if each terminal taxon was delimited by autapomorphies (Adams, 1998; Nadler, Adams et al., 2000). Given the combined evidence dataset, all terminal taxa are delimited by 3 or more autapomorphies, whereas with the LSU FA dataset, all terminal taxa had 2 or more autapomorphies except $S$. carpocapsae that had none. Using the LSU GR dataset, 4 taxa ( $S$. carpocapsae, Steinernema cubanum, S. longicaudum Chinese, and Steinernema oregonense) lacked autapomorphies. Analysis of the ITS
GR data (6 Steinernema taxa) revealed 5 autapomorphies for $S$. carpocapsae, and more than 5 autapomorphies each for $S$. monticolum, S. scapterisci, and S. siamkayai.

Patterns of character evolution were explored using the 2 composite molecular trees (Fig. 3) and the 4 trees inferred from combined evidence (Fig. 5). The range of consistency indexes for morphological characters (Table V) showed that a few characters used for developing evolutionary scenarios for Steinernema spp. or in producing classifications were explained by the minimum number of required changes. However, many others were inferred to be highly homoplastic. In addition, certain character states considered informative by previous investigators appear to represent ancestral (plesiomorphic) states. For instance, absence of a double-flapped epiptygma in first-generation females and presence of less than 8 ridges in the IJ lateral field have been emphasized as indicators of relationship among species (Mrácek and Bednarek, 1991; Hominick et al., 1997); however, both are inferred to represent ancestral states. Likewise, spicules of moderate size (average length: 60-70 $\mu \mathrm{m}$ ) and with a well-developed velum are also plesiomorphic states. The presence or absence of a tail mucro, and the spicule shape in first-generation males are also features widely used for diagnosis and to infer relationships between species (i.e., Hom- 


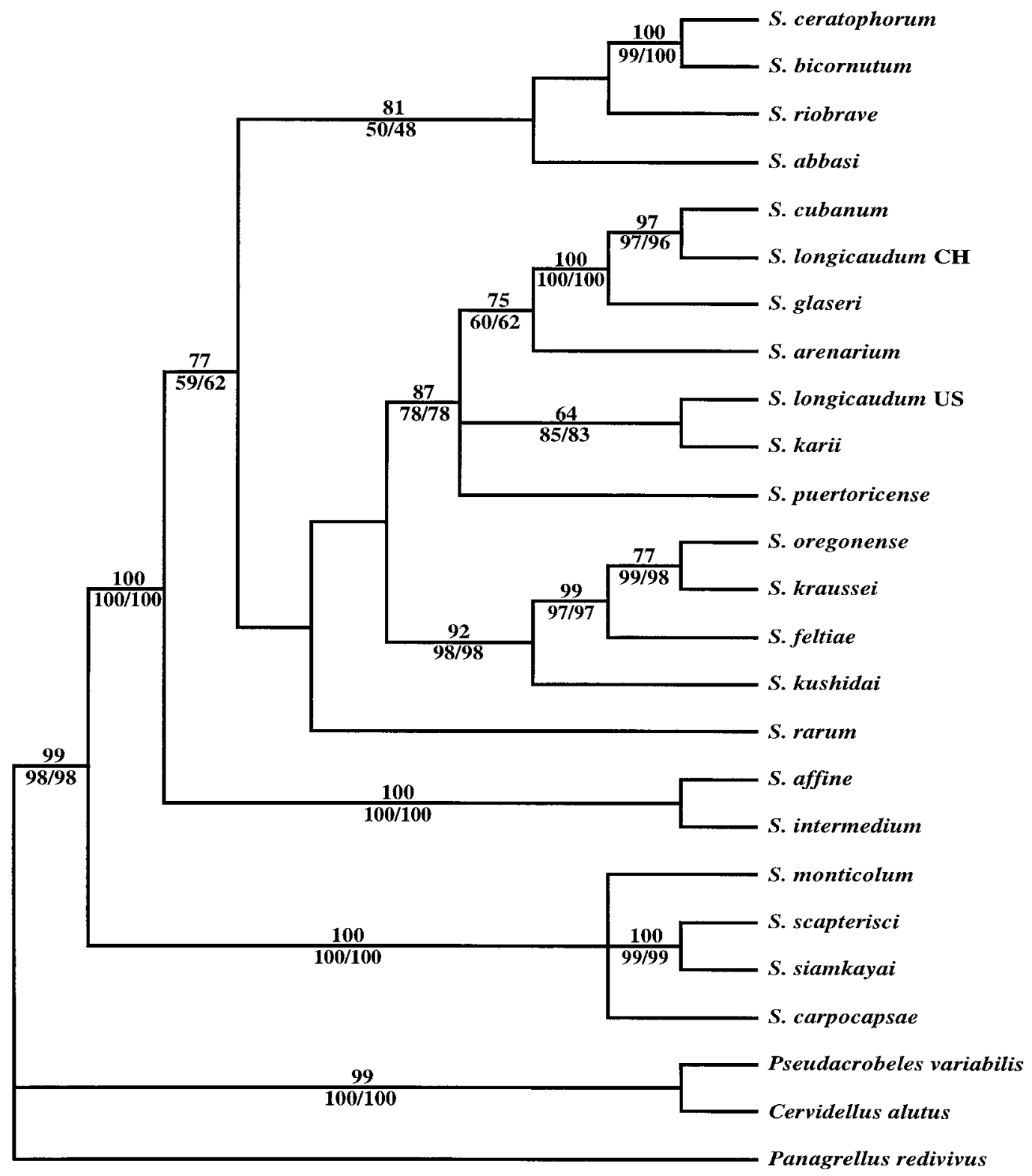

FIGURE 1. Strict consensus of 4 equally parsimonious trees inferred by maximum parsimony analysis of the full alignment dataset (LSU FA). Bootstrap percentages of clades are shown above internal nodes for the LSU FA analysis, and below internal nodes for LSU MUNC (left) and LSU GR (right) datasets. Topologies of the 4 individual trees (parenthetical notation) use numbers for taxa provided in Table I. Tree $1=$ $(6,((((()(((7,15), 9), 3),((14,11), 18)),(((17,12), 8), 13)), 19),((((16,5),(21,22)),((24,23), 25)),,(2,10))), 17), 20), 4))$. Tree $2=(6,(((((()((((7,15)$, $9), 3),(14,11)), 18),(((17,12), 8), 13)), 19),((((16,5),(21,22)),((24,23), 25)),(2,10))), 1), 20), 4))$. Tree $3=(6,((((((((7,15), 9), 3),((14,11)$, $18)),(((17,12), 8), 13)), 19),(((16,((21,22), 5)),((24,23), 25)),(2,10))), 1), 20), 4))$. Tree $4=(6,(((((()(((7,15), 9), 3),(14,11)), 18),(((17,12), 8)$, $13)), 19),(((16,((21,22), 5)),((24,23), 25)),(2,10))), 1), 20), 4))$.

inick et al., 1997); however, mapping suggests these characters are highly homoplasious. For the IJ, features considered useful for species diagnosis, including total body length, tail length, D\%, and E\% (Nguyen and Smart, 1996; Hominick et al., 1997; Kaya and Stock, 1997), are also highly homoplasious.

Parsimony mapping suggested that certain character states are shared derived characters for clades in the 6 trees that were analyzed. For example, the presence of hornlike structures in the IJ is a synapomorphy for S. ceratophorum and S. bicornutum. Additionally, certain features that have been described as informative for discrimination of taxa, such as the presence of a lamina notch in first-generation males and the presence of a tail spine in the IJ, are autapomorphic states in S. kushidai and $S$. affine, respectively. With respect to the lineage represented by $S$. scapterisci, S. siamkayai, S. carpocapsae, and S. monticolum, interpretation of the evolution of some character states differed between the molecular trees (Fig. 3) and the 4 combined evidence trees. For instance, the presence of a doubleflapped epiptygma in first-generation females and the presence of a thin (slightly developed) velum in S. scapterisci and $S$. siamkayai, was homoplastic in the molecular trees but synapomorphic in the combined trees. 


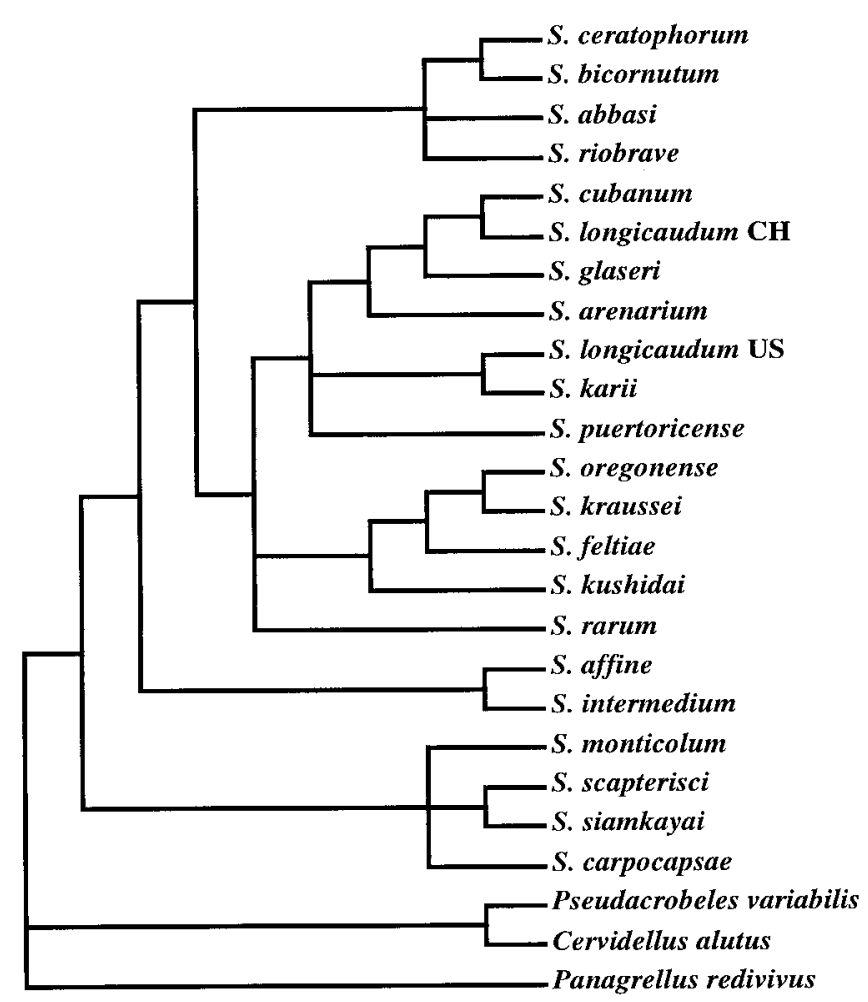

FIGURE 2. Strict consensus of all most-parsimonious trees inferred by maximum parsimony analysis of each individual LSU dataset (FA, MUNC, GR).

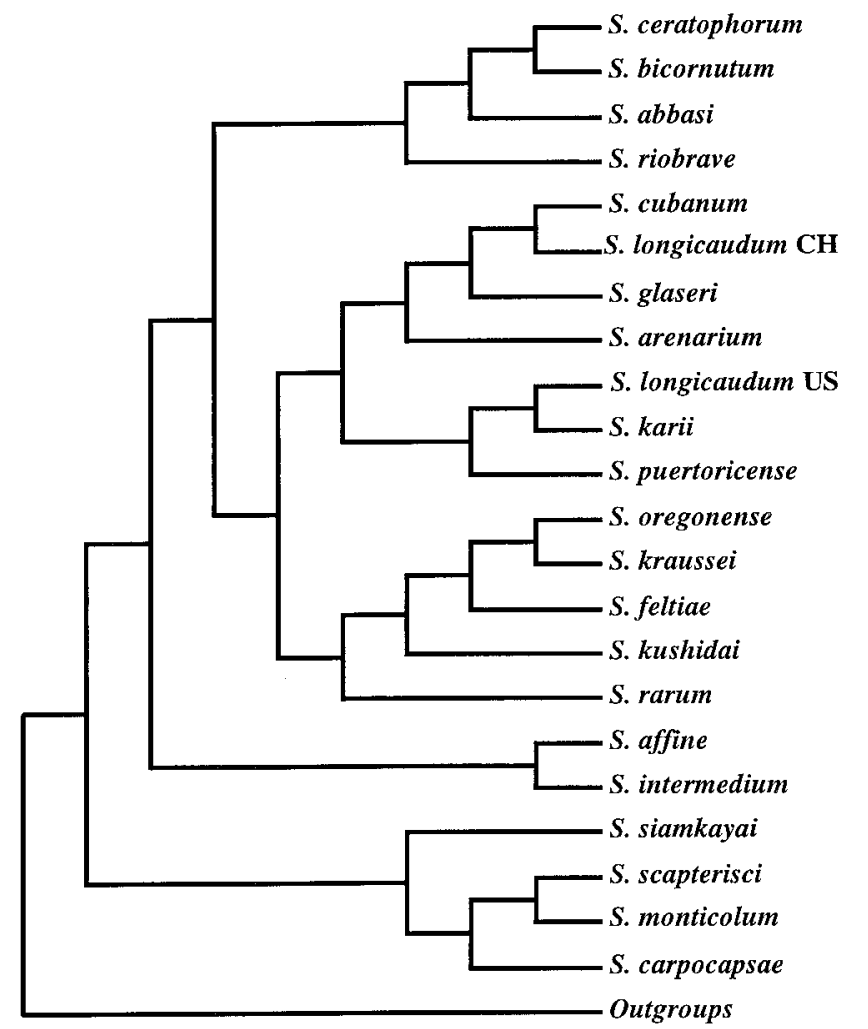

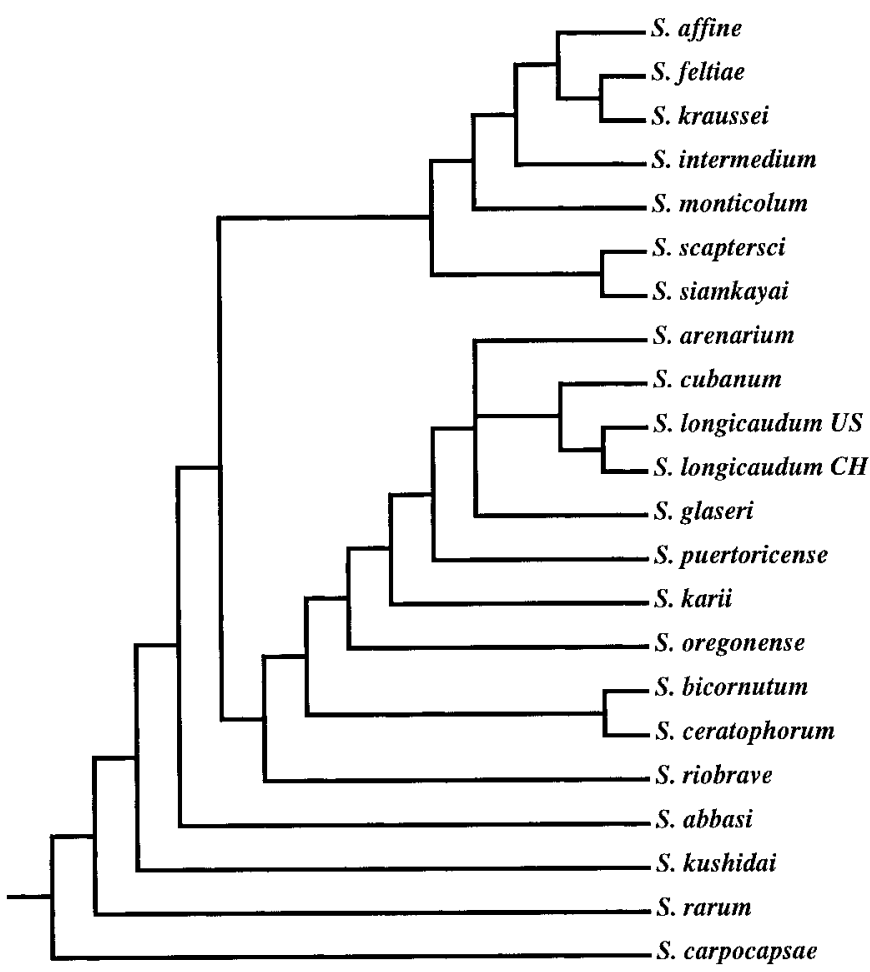

FIGURE 4. Strict consensus of 3 equally parsimonious trees inferred by maximumparsimonyanalysisofmorphologicaldata.

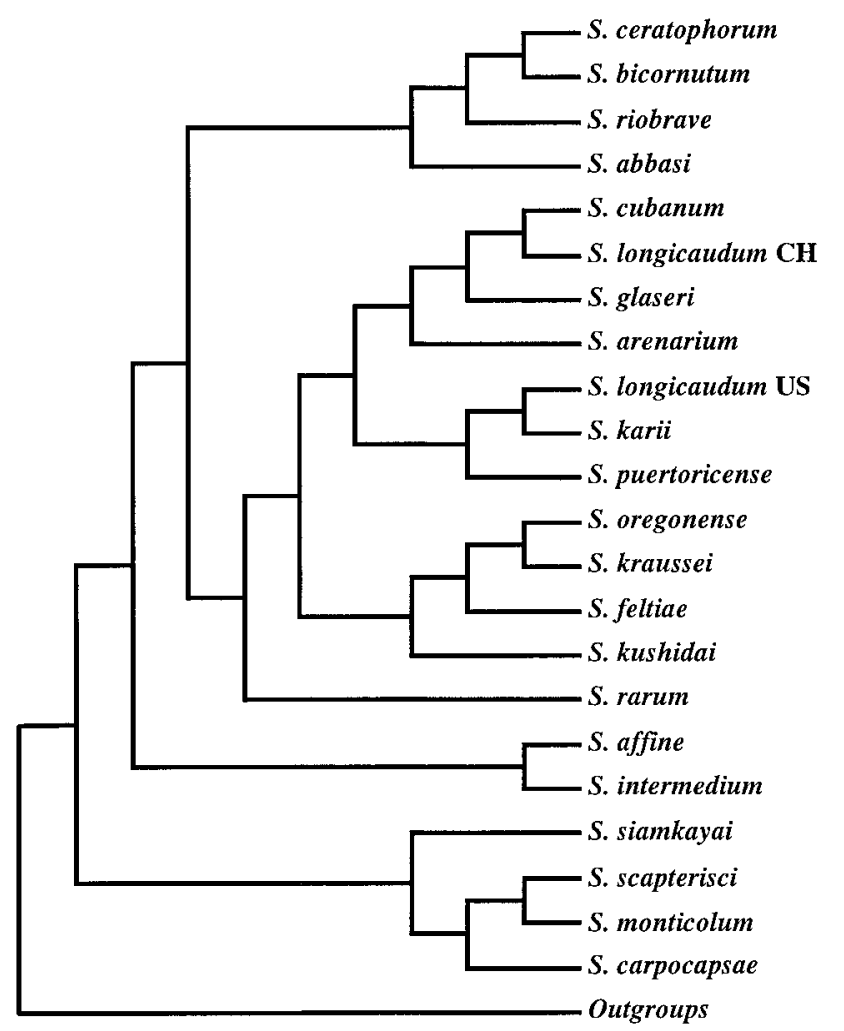

FIGURE3. Summaryofmolecularphylogeneticresultsshowing2most-parsimonioustreesinferredfromtheLSUGRdatasetwiththetopologyforSteinernemacarpocapsae, Steinernemamonticolum, Steinernemascapterisci, and Steinernema siamkayaiinferred fromcombined analysisofLSUGR and ITS GR datasets. 


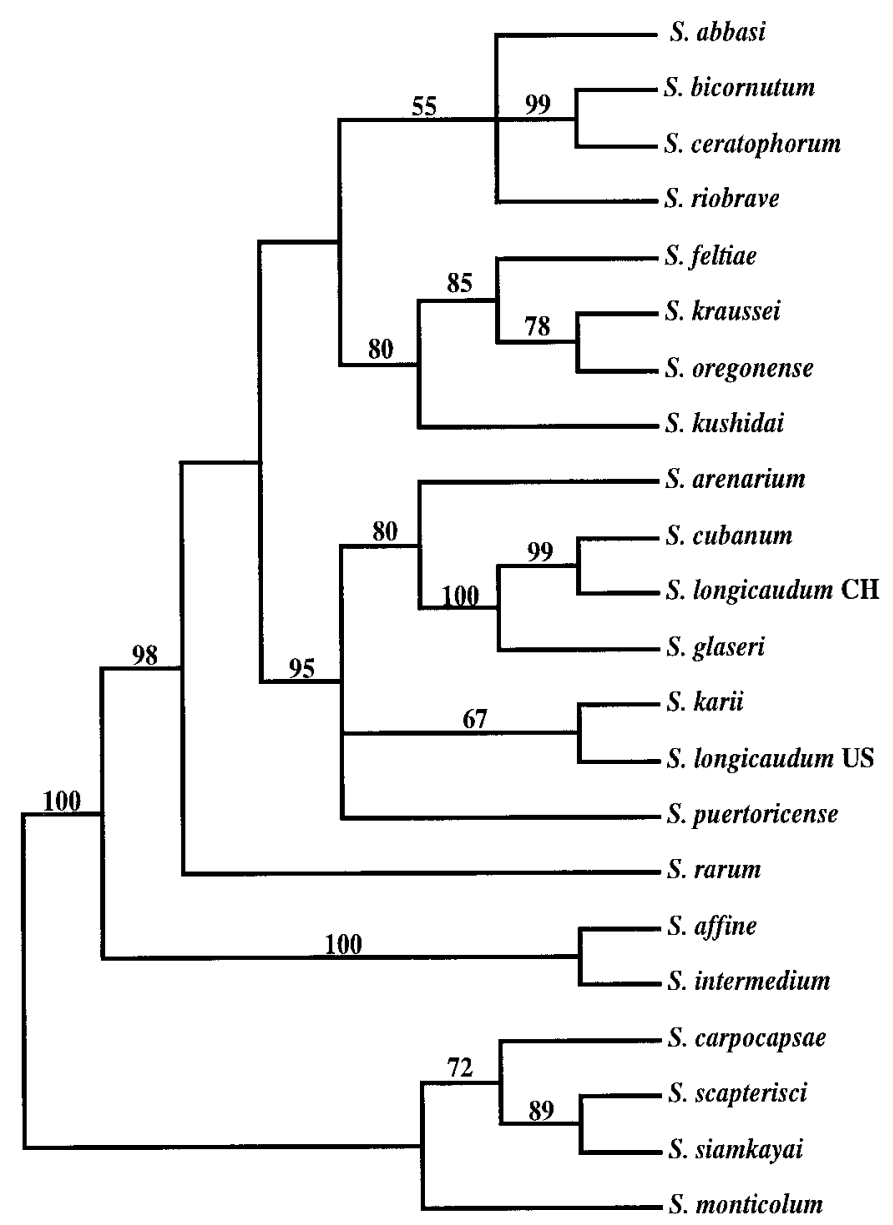

FIGURE 5. Strict consensus of 4 equally parsimonious trees inferred by maximum parsimony analysis of the combined evidence dataset (LSUGR andmorphology). Topologies of the individual trees (parentheticalnotation) use numbers for taxa provided in Table I. Tree $1=(1,((()(((2,10),((5),,(21$, 22) $), 16)), 19),((3,((7,15), 9)),((11,14), 18))),((8,(1217)), 13)), 20),(4,6)))$. Tree $2=(1,((((((2,10),((5,(21,22)), 16)), 19),((3,((7,15), 9)),((11,14)$, $18))),((8,(12,17)), 13)),(4,6)), 20))$. Tree $3=(1,((((((2,10),((5,(21,22))$, 16) $), 19),(((3((7,15), 9)),(11,14)), 18)),((8,(12,17)), 13)), 20),(4,6)))$. Tree $4=(1,((((((2,10),((5,(21,22)), 16)), 19),(((3,((7,15), 9)),(11,14))$, $18)),((8,(12,17)), 13)),(4,6)), 20))$.

\section{DISCUSSION}

The current study is the first comprehensive testable hypothesis of phylogenetic relationships for species in Steinernema. Previous studies have been of restricted utility due to limited taxon sampling (Reid, 1994; Liu, Berry, and Moldenke, 1997; Reid et al., 1997), use of sequence characters containing relatively few phylogenetically informative sites (Liu, Berry, and Moldenke, 1997), uncertainties of character homology (Liu and Berry, 1996), and potential nonindependence of characters (Reid et al., 1997). Reid et al.'s (1997) study, which was based on genetic distances calculated from rDNA RFLP band-sharing, included 10 identified species and 8 uncharacterized isolates. There are some areas of agreement between our results and the tree presented by Reid et al. (1997). For example, taxa with morphological similarities like $S$. affine and $S$. intermedium were closely related in both studies. In Reid et al. (1997), $S$. carpocapsae, S. scapterisci, and 2 uncharacterized isolates, Malaysia and SSL2 (likely S. siamkayai; see Stock et al., 1998)
TABLE IV. Statistical comparison of alternative trees using Templeton's and Kishino-Hasegawa tests.

\begin{tabular}{lcc}
\hline Topology & $\begin{array}{c}P^{*} \text { Templeton's } \\
\text { test }\end{array}$ & $\begin{array}{c}P^{*} \text { Kishino-Hasegawa } \\
\text { test }\end{array}$ \\
\hline Tree $1 \dagger$ & 1.0000 & 1.0000 \\
Tree $2 \dagger$ & 1.0000 & 1.0000 \\
Tree $3 \dagger$ & 1.0000 & 1.0000 \\
Tree $4 \dagger$ & 1.0000 & 1.0000 \\
Tree $5 \ddagger$ & $<0.0001$ & $<0.0001$ \\
\hline
\end{tabular}

* Probability of obtaining a more extreme test statistic under the null hypothesis of no difference between the 2 trees (2-tailed test).

$\dagger$ Maximum parsimony trees of 741 steps from analysis of combined evidence. Tree topologies described in Figure 5.

\# Single most parsimonious tree of 1,100 steps (taxon abbreviations from Table 1) inferred from combined evidence dataset and consistent with a constraint topology imposed from the 18S tree of Liu et al. (1997: fig. 3D): (1, (((2,)(16,(21, $22))),(((((3,(5,8)), 9), 17), 20), 10)),((((7,15),((11,14), 18)),(12,13)), 19)),(4,6)))$.

were monophyletic, as were the same species in our study. However, there is also much incongruence between our phylogenetic hypotheses and the tree presented by Reid et al. (1997). Unfortunately, it is not possible to assess if these regions of incongruence represent strongly supported alternative hypotheses based on different datasets, as the RFLP study did not include an evaluation of the relative reliability of clades.

Nucleotide sequences have also been used to investigate Steinernema phylogeny. Liu, Berry, and Moldenke (1997) inferred phylogenetic relationships for entomopathogens of the families Steinernematidae and Heterorhabditidae using partial $18 \mathrm{~S}$ rDNA sequences. These authors concluded that although these $18 \mathrm{~S}$ sequences were too conserved to resolve relationships among Heterorhabditis species, these data were "well-suited"

TABLE V. Consistency index range for morphological characters as inferred by parsimony mapping on 6 trees, including the 4 trees from analysis of combined evidence and 2 composite trees from molecular data.

\begin{tabular}{lll}
\hline \multicolumn{1}{c}{ Character } & No. states & C. I. range \\
\hline 1. Male tail mucro & 2 & $0.14-0.17$ \\
2. Male spicule shape & 3 & 0.29 \\
3. Male spicule manubrium & 3 & 0.22 \\
4. Male spicule lamina notch & 2 & 1.0 \\
5. Male spicule velum & 3 & $0.22-0.29$ \\
6. Male spicule rostrum & 3 & 0.25 \\
7. Male spicule tip & 4 & 0.30 \\
8. Male gubernaculum cuneus & 3 & 0.50 \\
9. Female tail & 4 & 0.25 \\
10. Female postanal swelling & 2 & 0.14 \\
11. Female vulval lips & 3 & 0.29 \\
12. Female epiptygma & 2 & $0.17-0.20$ \\
13. IJ hornlike structures & 2 & 1.0 \\
14. IJ tail spine & 2 & 1.0 \\
15. IJ lateral field pattern & 2 & 0.33 \\
16. Male spicule length & 4 & $0.38-0.43$ \\
17. Male D\% & 3 & 0.22 \\
18. Male SW ratio & 4 & 0.38 \\
19. IJ total body length & 4 & 0.38 \\
20. IJ D\% & 4 & $0.50-0.60$ \\
21. IJ E\% & 3 & 0.50 \\
22. IJ tail length & 4 & $0.33-0.38$ \\
\hline
\end{tabular}


for inferring phylogenetic relationships among Steinernema species. However, reanalysis of these $18 \mathrm{~S}$ data (using the alignment published by Liu, Berry, and Moldenke [1997]) revealed that these sequences were also highly conserved among Steinernema species, with only 12 parsimony-informative sites among the 8 Steinernema species sequenced. Relative to our results, statistical tests showed that Liu, Berry, and Moldenke's (1997) hypothesis is a significantly worse interpretation of our combined evidence dataset. In contrast, given the 7 species in common to the 2 studies, the tree topology consistent with our combined evidence trees is not a significantly worse interpretation of their $18 \mathrm{~S}$ data than the tree presented by Liu, Berry, and Moldenke (1997). These results suggest that the rather marked differences between the phylogenetic relationships inferred from partial $18 \mathrm{~S}$ and the combined (28S sequences and morphology) datasets may reflect a lack of robustness for the partial $18 \mathrm{~S}$ dataset.

In this investigation, parsimony analyses of $28 \mathrm{~S}$ rDNA data showed that the relative reliability of a small number of clades, as assessed by bootstrap resampling, was sensitive to alignment ambiguity. Therefore, molecular data used for combined evidence analysis excluded sites where positional homology was ambiguous. The phylogenetic hypotheses inferred from combined analysis of nucleotide and morphological data maximizes the explanatory power of available character data for these taxa (Eernisse and Kluge, 1993; Kluge, 1998). Therefore, these trees represent the best working hypotheses of evolutionary history for this genus, although interpretation of this phylogenetic hypothesis should be tempered by the likelihood that a substantial fraction of Steinernema species diversity is unknown (Hominick et al., 1996), and inclusion of unsampled clades may alter the phylogenetic hypothesis. In addition, these molecular inferences are based on data from a single locus. Despite these potential caveats, the resulting combined evidence trees are congruent with certain implicit or explicit expectations of relatedness based on overall morphological similarity or evolutionary interpretations of particular characters. However, trees inferred from combined evidence and those from sequence data alone also yielded some unexpected results when compared to traditional expectations.

The strict consensus of 4 most parsimonious trees from the combined evidence (Fig. 5) included several clades that received moderate-to-high support as inferred by bootstrap resampling. Several of these clades included species that share morphological similarities, and certain of these similarities were hypothesized to be synapomorphies based on most parsimonious interpretations of character evolution. Steinernema carpocapsae, S. siamkayai, S. scapterisci, and S. monticolum constituted the sister-clade to the remaining Steinernema species in analyses of combined evidence and in separate analyses of LSU datasets. This result was strongly supported by bootstrap resampling of these LSU data (Fig. 1). The 4 species within this clade were observed to have low levels of LSU sequence divergence and relatively few parsimony-informative LSU characters. This paucity of phylogenetically informative characters was addressed by sequencing more variable regions of rDNA (ITS-1 and ITS-2) to provide additional character data relevant to evolutionary relationships among the species in this clade. Phylogenetic relationships for these 4 species differed among inferences from combined analysis of LSU and ITS data (Fig. 3), combined analyses of LSU and morphological data (Fig. 5), and analysis of morphological data (Fig. 4). In particular, bootstrap MP analysis showed moderate support (89\%) for a sister-taxon relationship between $S$. scapterisci and S. siamkayai in combined analysis of morphological and LSU data, yet an identical value of nodal support was recovered depicting $S$. scapterisci and $S$. monticolum as sister species in combined analysis of LSU and ITS data. This is the only instance of conflict between MP trees inferred from different analyses where the conflicting relationships each appear to be supported reliably by bootstrap resampling.

A second clade that was strongly supported in analyses of the combined evidence and LSU datasets included $S$. affine and $S$. intermedium as sister species. These species are extremely similar morphologically, their only distinguishing feature being the presence of a spine on the tail tip of infective juveniles of S. affine. Both of these taxa were delimited by nucleotide autapomorphies (sensu Adams, 1998; Nadler, Adams et al., 2000); 15 ( $S$. affine) and 16 (S. intermedium) autapomorphies in the LSU FA dataset, and 6 (S. affine) and 10 (S. intermedium) autapomorphies in the LSU MUNC dataset, providing molecular support for their status as species.

The remaining 16 Steinernema taxa were represented as a strongly supported clade in the combined evidence tree $(97 \%$ bootstrap support) but received moderate support (LSU FA dataset) or weak (LSU MUNC, LSU GR datasets) support as inferred from LSU datasets. This clade is a morphologically heterogeneous group of species that includes several subclades that were strongly supported by various data partitions. The largest subclade, which included 7 taxa (Steinernema arenarium, S. cubanum, S. longicaudum CH, S. longicaudum US, S. glaseri, S. karii, and Steinernema puertoricense), received strong (combined evidence) or moderate (LSU datasets) bootstrap support. Six of these species also share the characteristics of having the largest infective juveniles and 8 ridges in the lateral field; however, neither of these characteristics were an exclusive apomorphy for these species. Nested within this clade of 7 taxa are additional subclades receiving moderate-to-high support in bootstrap MP analysis of the combined evidence and LSU datasets.

One notable and unexpected conflict between the morphological and molecular analyses involves S. longicaudum that is represented by 2 isolates in these analyses. These 2 isolates (Chinese and United States) are morphologically indistinguishable. However, despite their monophyly in analysis of morphological data (Fig. 4), these isolates showed substantial sequence divergence $(7.1 \%)$ and were polyphyletic in phylogenetic analyses of combined evidence and LSU datasets. In the combined evidence and LSU datasets, the Chinese isolate of S. longicaudum was always the sister species to $S$. cubanum, and this result was strongly supported by bootstrap resampling. In contrast, the United States isolate of S. longicaudum was the sister species to $S$. karii in combined evidence and LSU datasets, but this result received low-to-moderate bootstrap support. These results indicate that these morphologically similar isolates of $S$. longicaudum are not conspecific. Additional investigations, including determining the nucleotide sequence of topotype isolates of this species are required to provide a basis for identifying $S$. longicaudum sensu stricto and to provide data for describing what appears to be a new species. Despite this and 
other conflicts between trees inferred from molecular data versus results based only on morphology, it is notable that a clade of 4 taxa, S. arenarium, S. cubanum, S. longicaudum Chinese, and Steinernema glaseri, was recovered in analyses of combined evidence and LSU datasets, and (along with the morphologically similar $S$. longicaudum US) was present in all most parsimonious trees inferred from morphological data.

Another clade receiving moderate bootstrap support (80\%) in the combined evidence analysis and strong support in analyses of the LSU datasets (92-98\%) included S. kushidai, Steinernema feltiae, Steinernema kraussei, and $S$. oregonense. With the exception of $S$. kushidai that can be readily identified by morphological criteria, the remaining 3 species are so similar that they are easily misidentified. Yet, each of these species was delimited by 19-20 nucleotide autapomorphies, and S. feltiae, $S$. kraussei, and S. oregonense were strongly supported as monophyletic in analyses of the LSU datasets (Fig. 1). Steinernema kraussei, S. feltiae, and S. oregonense, or species pairs from this clade, e.g., $S$. feltiae and $S$. oregonense, have also been suggested to be closely related based on previously published morphological or molecular evidence (Liu and Berry, 1996). All analyses of molecular or combined evidence datasets recovered these 3 species as a clade and represented $S$. kraussei and $S$. oregonense as sister taxa. In contrast, MP trees from the morphological analysis did not recover this clade and represented S. kraussei and S. feltiae as sister taxa. However, the kraussei-feltiae clade was not reliably supported by morphological characters as assessed by bootstrap resampling.

Steinernema ceratophorum, S. bicornutum, S. abbasi, and $S$. riobrave were members of a subclade within the 16-taxon group in most-parsimonious trees from combined evidence and LSU datasets; however, this clade was not reliably supported in bootstrap MP analyses, except for the LSU FA dataset, where it received moderate support. Due to topological differences among trees, $S$. abbasi and $S$. riobrave were unresolved within strict consensus trees for each of these datasets. However, there was strong bootstrap support in the combined evidence and LSU analyses for $S$. ceratophorum and $S$. bicornutum as sister species, and these taxa were also monophyletic in all $3 \mathrm{MP}$ trees inferred from morphological data. These species share unique hornlike structures in the cephalic region of infective juveniles that are hypothesized to be a shared-derived character, as inferred from analysis of morphological data and by mapping this character on the combined evidence trees.

A general goal of this study was to explore patterns of character evolution using the best estimates of phylogeny. Although these best estimates are trees based on combined evidence, character evolution was also explored on 2 trees (Fig. 3) representing an hypothesis based only on molecular data (LSU and ITS sequences). Overall, our results suggest that most of the morphological features that have been emphasized for classification and assessing relationships represent either plesiomorphic states or highly homoplastic characters. For example, given the 6 trees used to examine character evolution, only 3 characters changed without homoplasy over these trees. Two of these characters were autapomorphic (lamina notch presence/absence, tail spine presence/absence), and 1 character, presence of hornlike structures in infective juveniles of $S$. ceratophorum and $S$. bicornutum, was synapomorphic. In considering character evolution within the clade of S. monticolum, S. scapterisci, S. siamkayai, and S. car- pocapsae, different results were obtained for 3 characters depending on whether topologies based on combined evidence versus those based on a composite of $28 \mathrm{~S}$ and ITS data were used. In each case, the 4 trees based on combined evidence yielded a synapomorphic character distribution for these morphological characters (spicule velum slightly developed, epiptygma present, spicule length 71-90 $\mu \mathrm{m}$ ), whereas the 2 composite molecular trees (Fig. 3) required homoplasy to most parsimoniously explain evolution of these characters. Several character states emphasized by previous investigators as providing evidence of relatedness among Steinernema species were inferred to be plesiomorphic states by character mapping on all 6 trees. These character states included absence of a lamina notch, presence of a well-developed velum, presence of a short Y- or V-shaped cuneous in the gubernaculum of first-generation males, absence of an epiptygma in first-generation females, lateral field pattern with less than 8 ridges, and absence of a tail spine in third-stage infective juveniles.

In addition to morphological characters that were included in the combined analysis, certain other features of these species merit consideration relative to these phylogenetic hypotheses. For example, sister species of Steinernema show no obvious relationship to geographical site of isolation (see Table I). However, the geographic range of most Steinernema species has not been thoroughly documented, and it is unlikely that the geographic origins of these particular isolates necessarily reflect centers of diversification for species. Likewise, the obligate bacterial mutualists of Steinernema, Xenorhabdus spp., have yet to be fully described with respect to their species diversity. Five species of Xenorhabdus have been described based on culture characteristics and biochemical criteria (Boemare et al., 1996). It is notable that certain clades of Steinernema harbor the same Xenorhabdus species. For example, S. feltiae and S. kraussei each have Xenorhabdus bovienii (the symbiont of $S$. oregonense has not been characterized). Similarly, S. cubanum and S. glaseri have Xenorhabdus poinarii (likewise, the symbiont of $S$. longicaudum $\mathrm{CH}$ has not been characterized). These findings suggest that preliminary sequenced-based investigations of $\mathrm{Xe}$ norhabdus phylogeny (Rainey et al., 1995; Liu, Berry, Poinar, and Moldenke, 1997; Stackebrandt et al., 1997) need to be extended to test the hypothesis of nematode-symbiont cophylogeny and potentially to uncover additional lineages within classically described Xenorhabdus species.

Interpretation of results from apomorphy-based species delimitation varied depending on which dataset was used for analysis. Relying on combined evidence, all terminal taxa were delimited as species by autapomorphies. For molecular datasets, only the LSU FA dataset delimited most terminal taxa unequivocally. The more conservative (with respect to multiple sequence alignment) LSU GR dataset lacked autapomorphies for $S$. carpocapsae, S. cubanum, S. longicaudum Chinese, and $S$. oregonense. However, analysis of the ITS GR dataset yielded autapomorphies for $S$. carpocapsae (the 3 other species were not sequenced for ITS regions). These results illustrate how consideration of alignment ambiguity for molecular sequences can affect interpretation of species using evolutionary (including apomorphy-based) approaches. However, because the combined evidence represents our most comprehensive phylogenetic dataset (and it excludes $28 \mathrm{~S}$ characters that were potentially alignment ambiguous), it is notable that each of these terminal taxa shows evidence of historical independence (autapomor- 
phies), consistent with their delimitation as separate species. Clearly, confidence in the exclusive and fixed nature of these autapomorphies needs to be increased thorough population-level sampling of these taxa.

\section{ACKNOWLEDGMENTS}

We thank all our colleagues (listed in Table I) who kindly provided nematode isolates. This work was supported in part by an NSF-PEET grant (DEB-9712355) to S.A.N. and J. G. Baldwin, and by a JastroShields grant to J.F.C.

\section{LITERATURE CITED}

ADAMS, B. J. 1998. Species concepts and the evolutionary paradigm in modern nematology. Journal of Nematology 30: 1-21.

- , A. M. Burnell, AND T. O. Powers. 1998. A phylogenetic analysis of Heterorhabditis (Nemata: Rhabditidae) based on internal transcribed spacer 1 DNA sequence data. Journal of Nematology 30: $22-39$.

Ausubel, F. M., R. Brent, R. E. Kingston, D. D. Moore, J. G. SeidMAN, J. A. Smith, AND K. Struhl. 1989. Short protocols in molecular biology. Greene Publishing Associates and Wiley-Interscience, New York, New York, 387 p.

Blaxter, M. L., P. De Ley, J. R. Garey, L. X. Liu, P. Schheldeman, A. Vierstraete, J. R. Vanfleteren, L. Y. Mackey, M. Dorris, L. M. Frisse, J. T. VIDA, AND W. K. Thomas. 1998. A molecular evolutionary framework for the phylum Nematoda. Nature 392: 7175.

- M. DORRIS, AND P. DE LEY. 2000. Patterns and processes in the evolution of animal parasitic nematodes. Nematology 2: 43-55.

Boemare, N. E., R. J. Akhurst, and R. G. Mourant. 1993. Deoxyribonucleic acid relatedness between Xenorhabdus spp. (Enterobacteriaceae), symbiotic bacteria of entomopathogenic nematodes, with a proposal to transfer Xenorhabdus luminescens to a new genus Photorhabdus gen. nov. International Journal of Systematic Bacteriology 43: 249-255.

— C. Laumond, And H. Mauleon. 1996. The entomopathogenic nematode-bacterium complex: Biology, life cycle and vertebrate safety. Biocontrol Science and Technology 6: 337-346.

Brown, I. M., AND R. GAUGLER. 1997. Temperature and humidity influence emergence and survival of entomopathogenic nematodes. Nematologica 43: 363-375.

Campbell, J. F., And R. Gaugler. 1997. Inter-specific variation in the entomopathogenic nematode foraging strategy: Dichotomy or variation along a continuum? Fundamental and Applied Nematology 20: 393-398.

Crandall, K. A., And J. F. Fitzpatrick, JR. 1996. Crayfish molecular systematics: Using a combination of procedures to estimate phylogeny. Systematic Biology 45: 1-26.

De Doucet, M., M. A. Bertolotti, A. L. Giayetto, and M. B. MiRANDA. 1999. Host range, specificity, and virulence of Steinernema feltiae, Steinernema rarum, and Heterorhabditis bacteriophora (Steinernematidae and Heterorhabditidae) from Argentina. Journal of Invertebrate Pathology 73: 237-242.

Dix, I., H. Koltai, I. Glazer, And A. Burnell. 1994. Sperm competition in mated first generation hermaphrodite females of the HP88 strain of Heterorhabditis (Nematoda: Heterorhabditidae) and progeny sex ratios in mated and unmated females. Fundamental and Applied Nematology 17: 17-27.

Eernisse, D. J., AND A. G. KLUGE. 1993. Taxonomic congruence versus total evidence, and amniote phylogeny inferred from fossils, molecules and morphology. Molecular Biology and Evolution 10: $1170-1195$.

Elawad, S., W. Ahmad, AND A. P. ReID. 1997. Steinernema abbasi sp.n. (Nematoda: Steinernematidae) from the Sultanate of Oman. Fundamental and Applied Nematology 20: 435-442.

Félix, M.-A., P. De Ley, R. J. Sommer, L. Frisse, S. A. Nadler, K. Thomas, J. Vanfleteren, And P. Sternberg. 2000. Evolution of vulva development in the Cephalobina (Nematoda). Developmental Biology 221: 68-86.

Forst, S., AND K. NEALSON. 1996. Molecular biology of the symbiotic- pathogenic bacteria Xenorhabdus spp. and Photorhabdus spp. Microbiological Reviews 60: 1-43.

Freed, R., S. P. Eisensmith, S. Goetz, R. Reicosky, V. W. Smail, and P. Wolberg. 1991. User's guide to MSTAT-C: A software program for the design, management, and analysis of agronomic research experiments. Michigan State University, East Lansing, Michigan.

Grenier, E., E. Bonifassi, P. Abad, And C. Laumond. 1996. Use of species specific satellite DNAs as diagnostic probes in the identification of Steinernematidae and Heterorhabditidae entomopathogenic nematodes. Parasitology 11: 483-489.

Griffin, C. T., M. J. Downes, AND W. Block. 1990. Tests of Antarctic soils for insect parasitic nematodes. Antarctic Science 2: 221-222.

Hominick, W. M., B. R. Briscoe, F. G. Del Pino, J. Heng, D. J. Hunt, E. Kozodoy, Z. Mrácek, K. B. Nguyen, A. P. Reid, S. Spiridonov, P. Stock, D. Sturhan, C. Waturu, and M. Yoshida. 1997. Biosystematics of entomopathogenic nematodes: Current status, protocols and definitions. Journal of Helminthology 71: 271-298.

- A. P. ReID, D. A. BoHAN, AND B. R. BRIscoe. 1996. Entomopathogenic nematodes: Biodiversity, geographical distribution and the convention on biological diversity. Biocontrol Science and Technology 6: 317-331.

Joyce, S. A., C. T. Griffin, And A. M. Burnell. 1994. The use of isoelectric focusing and polyacrylamide gel electrophoresis of soluble proteins in the taxonomy of the genus Heterorhabditis (Nematoda: Heterorhabditidae). Nematologica 40: 601-612.

Kampfer, S., C. Sturmbauer, And J. OtT. 1998. Phylogenetic analysis of rDNA sequences from adenophorean nematodes and implications for the Adenophorea-Secernentea controversy. Invertebrate Biology 117: 29-36.

Kaya, H. K., and S. P. Stock. 1997. Techniques in insect nematology. In Manual of techniques in insect pathology, L. A. Lacey (ed.). Biological Techniques Series, Academic Press, San Diego, California, p. 281-324.

Kishino, H., AND M. HASEgawa. 1989. Evaluation of the maximum likelihood estimate of the evolutionary tree topologies from DNA sequence data, and the branching order in hominoidea. Journal of Molecular Evolution 29: 170-179.

KLuge, A. G. 1998. Total evidence or taxonomic congruence: Cladistics or consensus classification. Cladistics 14: 151-158.

LIU, J., AND R. E. BERRY. 1995. Determination of PCR conditions for RAPD analysis in entomopathogenic nematodes (Rhabditida: Heterorhabditidae and Steinernematidae). Journal of Invertebrate $\mathrm{Pa}$ thology 65: 79-81.

— AND -1996 . Phylogenetic analysis of the genus Steinernema by morphological characters and randomly amplified polymorphic DNA fragments. Fundamental and Applied Nematology 19: 463-469.

$\longrightarrow, \longrightarrow$, AND A. F. Moldenke. 1997. Phylogenetic relationships of entomopathogenic nematodes (Heterorhabditidae and Steinernematidae) inferred from partial $18 \mathrm{~S}$ rRNA gene sequences. Journal of Invertebrate Pathology 69: 246-252.

,- G. Poinar, And A. Moldenke. 1997. Phylogeny of Photorhabdus and Xenorhabdus species and strains as determined by comparison of partial $16 \mathrm{~S}$ rRNA gene sequences. International Journal of Systematic Bacteriology 47: 948-951.

MrÁCEK, Z., AND A. BEDNAREK. 1991. The morphology of the lateral field of infective juveniles of entomopathogenic nematodes of the family Steinernematidae (Rhabditida). Nematologica 37: 63-71.

NADLER, S. A. 1992. Phylogeny of some ascaridoid nematodes, inferred from comparison of $18 \mathrm{~S}$ and $28 \mathrm{~S}$ rRNA sequences. Molecular Biology and Evolution 9: 932-944.

, B. J. Adams, E. T. Lyons, R. L. Delong, and S. R. Melin. 2000. Molecular and morphometric evidence for separate species of Uncinaria (Nematoda: Ancylostomatidae) in California sea lions and northern fur seals: Hypothesis testing supplants verification. Journal of Parasitology 86: 1099-1106.

, E. P. Hoberg, D. S. S. Hudspeth, and L. G. Rickard. 2000. Relationships of Nematodirus species and Nematodirus battus isolates (Nematoda: Trichostrongyloidea) based on nuclear ribosomal DNA sequences. Journal of Parasitology 86: 588-601.

- AND D. S. S. HuDSPETH. 1998. Ribosomal DNA and phylogeny of the Ascaridoidea (Nemata: Secernentea): Implications for mor- 
phological evolution and classification. Molecular Phylogenetics and Evolution 10: 221-236.

-, AND - 2000. Phylogeny of the Ascaridoidea (Nematoda: Ascaridida) based on three genes and morphology: Hypotheses of structural and sequence evolution. Journal of Parasitology 86: 380393.

NGUYen, K. B., AND G. C. SMART, JR. 1996. Identification of entomopathogenic nematodes in the Steinernematidae and Heterorhabditidae (Nemata: Rhabditina). Journal of Nematology 28: 286-300. , AND - 1997. Scanning electron microscope studies of spicules and gubernacula of Steinernema spp. (Nemata: Steinernematidae). Nematologica 43: 465-480.

POINAR, G. O., JR. 1990. Taxonomy and biology of Steinernematidae and Heterorhabditidae. In Entomopathogenic nematodes in biological control, R. Gaugler and H. K. Kaya (eds.). CRC Press, Boca Raton, Florida, p. 23-61.

1993. Origins and phylogenetic relationships of the entomophilic rhabditids Heterorhabditis and Steinernema. Fundamental and Applied Nematology 16: 333-338.

Rainey, F. A., R.-U. Ehlers, AND E. Stackebrandt. 1995. Inability of the polyphasic approach to systematics to determine the relatedness of the genera Xenorhabdus and Photorhabdus. International Journal of Systematic Bacteriology 45: 379-381.

REID, A. P. 1994. Molecular taxonomy of Steinernema. In Genetics of entomopathogenic nematode-bacterium complexes, A. M. Burnell, R.-U. Ehlers and J. P. Mason (eds.). European Commission Luxembourg, Luxembourg City, Luxembourg, p. 49-58.

, AND W. M. Hominick. 1993. Cloning of rDNA repeat unit from British entomopathogenic nematode (Steinernematidae) and its potential for species identification. Parasitology 107: 529-536.

- - AND B. R. BRISCOE. 1997. Molecular taxonomy and phylogeny of entomopathogenic nematode species (Rhabditidae: Steinernematidae) by RFLP analysis of the ITS region of the ribosomal DNA repeat unit. Systematic Parasitology 37: 187-193.

Sanderson, M. J., M. J. Donoghue, W. Piel, and T. Eriksson. 1994. TreeBASE: A prototype database of phylogenetic analyses and an interactive tool for browsing the phylogeny of life. American Journal of Botany 81: 183.

Simoes, N., AND J. S. SosA. 1996. Pathogenicity and host specificity of entomopathogenic nematodes. Biocontrol Science and Technology 6: $403-411$.
Simon, C. 1983. A new coding procedure for morphometric data with an example from periodical cicada wing veins. In Numerical taxonomy, J. Felsenstein (ed.). Springer-Verlag, Berlin, Germany, p. 378-383.

Stackebrandt, E., R.-U. Ehlers, And F. A. Rainey. 1997. Xenorhabdus and Photorhabdus. Are they sister genera or are their members phylogenetically intertwined? Symbiosis 22: 59-65.

Sтоск, S. P. 1997. Heterorhabditis hepialius Stock, Strong and Gardner, 1996 a junior synonym of $H$. marelatus Liu and Berry, 1996 (Rhabditida: Rhabditidae) with a redescription of the species. Nematologica 43: 455-463.

, V. SAMSOOK, AND A. P. REID. 1998. A new entomopathogenic nematode Steinernema siamkayai sp. n. (Rhabditida: Steinernematidae) from Thailand. Systematic Parasitology 41: 105-113.

SwOFFord, D. L. 1993. Phylogenetic analysis using parsimony, version 3.1.1. Illinois Natural History Survey, Urbana, Illinois, 257 p. . 1998. PAUP*. Phylogenetic analysis using parsimony (and other methods), version 4. Sinauer Associates, Sunderland, Massachusetts, $257 \mathrm{p}$.

Tallosi, B., A. Peters and R. U. Ehlers. 1994. Steinernema bicornutum (Rhabditida: Steinernematidae) from Vojvodina, Yugoslavia. Russian Journal of Nematology 3: 71-80.

Templeton, A. R. 1983. Phylogenetic inference from restriction endonuclease cleavage site maps with particular reference to the humans and apes. Evolution 37: 221-244.

Thomas, W. K., J. T. Vida, L. M. Frisse, M. Mundo, AND J. G. BaldWIN. 1997. DNA sequences from formalin-fixed nematodes: Integrating molecular and morphological approaches to taxonomy. Journal of Nematology 29: 250-254.

Thompson, J. D., T. J. Gibson, F. Plewniak, F. Jeanmougin, and D. G. HIGGINS. 1997. The CLUSTAL_X windows interface: Flexible strategies for multiple sequence alignment aided by quality analysis tools. Nucleic Acids Research 25: 4876-4882.

Waturu, C. N., D. J. Hunt, AND A. P. ReID. 1997. Steinernema karii sp. n. (Nematoda: Steinernematidae), a new entomopathogenic nematode from Kenya. International Journal of Nematology 7: 6875.

WoOdRING, J. L., AND H. K. KAYA. 1988. Steinernematid and heterorhabditid nematodes. A handbook of techniques. Southern Cooperative Series Bulletin 331, Arkansas Agricultural Experiment Station, Fayetteville, Arkansas, 30 p. 